\title{
A Learning Mindset Needed from Faculty in Online Program Management and University Partnership Business Model
}

\author{
Swati Ramani \\ Southern California University of Health Sciences, USA \\ ramaniswati@gmail.com
}

\begin{abstract}
Many universities are transforming themselves from single mode on-campus universities to dual mode universities after recognizing the importance of providing online education programs and the kinds of opportunities they offer. These universities often have their faculty work with instructional designers (ID) in-house or at times outsource online course development to an Online Program Management (OPM) provider. The ID process involves course development where faculty and instructional designer (ID) work together to build the online course. A gap exists in the literature around how faculty interact with such IDs provided by OPMs and what impact the ID process has in their teaching design, and their pedagogical knowledge and development. This research uses a Case Study to analyze how the nature and dynamics of the ID process in a business partnership between a research university and an OPM provider influence faculty. This case study included a private research university that had recently joined a partnership with an Online Program Management Provider (OPM) to develop and offer online Master's degree programs. The Activity Theory conceptual framework was used to direct inquiry and analysis. Results show that the impact on faculty pedagogical knowledge and development is different for each faculty and is dependent on faculty assumptions, personality, attitudes, training in pedagogy and technology, and past online teaching experiences. A learning mindset from the faculty side is very important to get the best of this relationship. This research supports e-learning practice by guiding that faculty should not be participating just due to the pressure by their upper-level management but because they really want to teach online. Faculty should be ready to check their own assumptions and knowledge they have about pedagogy before getting into this process. This study is a novel approach to understand the impact on faculty teaching design using Activity Theory framework. It shows how Activity Theory could be a useful technique to solve problems in e-learning research and practice.
\end{abstract}

Keywords: Faculty Development; OPM-University Model; Activity Theory

\section{Introduction}

Online learning uses a different platform, builds communities in different ways, demands different pedagogies and requires different choices for curriculum as compared to face-to-face courses and programs (Morris and Stommel, 2016). Many studies show that teaching online requires a different pedagogy and skill set as compared to the traditional classroom (Fetherston, 2001; Hardy and Bower, 2004; Oliver, 2002; Boling et al., 2012). Online teachers are faced with new pedagogical issues including student interactions, course content design and delivery, multiple levels of communication, new types of assignments, and different sets of evaluation (Boling et al., 2012). According to the research conducted by Boling et al. (2012), developing and teaching online courses necessitates adaptations in teaching practices. A persona change occurs when a faculty member transitions from face-to-face teaching to the online classroom (Phillips, 2008). Use of technology in this field demands a shift from a teaching- to a learning-centered paradigm (Boling et al., 2012; Fink, 2013; 2013a). Faculty may not be willing to teach online because of their experience with the dynamics of exchanging eye contact, observing body language and portraying an engaging personality to enhance student interest (Crawley, Fewell, and Sugar, 2009). Teaching online requires a level of planning that usually is not practiced for face-to-face courses (McQuiggan, 2007). Online courses that do not employ evidence-based instructional design practices can cause lack of sufficient student engagement and interactions and can have a negative impact on the student learning experience that eventually can affect student retention (Vasser, 2010). Traditional courses converted to online courses without proper implementation of online pedagogical principles can result in an ill-structured design and affect learning (Vasser, 2010). Without the help and oversight of an instructional designer (ID), faculty could continue to see their role only as delivering content and as such do not follow a student-centered approach (McQuiggan, 2007). To convert a face-to-face course into an online course, faculty can benefit by working with ID's who help with faculty development in the context of integrating pedagogy with technology and guide on how to deliver/teach their course content online.

The instructional design process involves course development where faculty and ID work together to build the online course from scratch or convert an existing face-to-face course to an online course. During this instructional design process faculty and ID spend many months together to design an online course. During this time, they meet regularly every week and exchange ideas and create, update or revise the course materials to ISSN 1479-4403 
have it prepared for online course delivery. During this process the faculty and ID need to work in coordination and trust each other but at times the interactions can be difficult and problematic and can create conflicts (InsideHigherEd.com, 2017; 2017a). For faculty, who have been teaching for a very long time, can sometimes face difficulty in working with an ID because they are not comfortable with the changes and structure needed to convert traditional course to an online modality (Halupa, 2019). For ID's, who have degrees and certificates in instructional design, very well know the principles involved in designing an online course, however the faculty may be very resistant in implementing the suggested changes and may not understand the needed time, critical thinking, and collaboration that needs to be involved (InsideHigherEd.com, 2017; 2017a).

Over the past 20 years, universities have been adopting online programs in addition to existing on-the-ground programs (Casey, 2008; Essary, 2014). Many universities are transforming themselves from single mode oncampus universities to dual mode universities after recognizing the importance of providing online/distance education programs and the kinds of opportunities they offer (Rovai and Downey, 2010). The COVID-19 pandemic has accelerated the need for online programs (Fain, 2020). Distance education helps universities reach out to the so-called 'non-traditional' students in geographically dispersed locations, with family and employment responsibilities (Fresen, 2018). Other opportunities and advantages include just-in-time learning; increased easy access to learning materials; removal of time, place and situational barriers; cost effectiveness; greater accountability; personalization of educational experience; provision of future employment skills for students; and effective support for lifelong learning (Anderson and Elloumi, 2004). Online learning programs are gaining importance and are now the new standards for delivering learning and training to those learners who want the flexibility and support of an adult learner lifestyle (Allen and Seaman, 2017; Ozcan and Yildirim, 2018). The importance of distance education is acknowledged by many universities across the world (Rovai and Downey, 2010). Over the period 2013-2017, enrollment in at least one distance education course grew by $28.77 \%$ $(1,493,490)$ (Bradford, 2019). In a survey of 2,800 Chief Academic Officers, 69.1 percent reported that online education was critical to their institution's long-term strategy (Allen and Seaman, 2013, p. 4). Moreover, many universities are continuing to add distance education programs and grow existing ones even while campusbased enrollments are declining (Allen and Seaman, 2016).

Many higher education institutions believe that they must adopt online programs to better serve their constituencies, but making this decision requires faculty to adopt a new mode of teaching. Higher education institutions can build infrastructure internally (ID staff) to support their online program initiatives or they can partner with management organizations (Online Program Management Providers, OPMPs) that offer some or all of the services needed to make online programs successful. These services include marketing, admissions, and instructional design. This paper presents a case study that describes the interactions between the faculty at a research university, an online program management provider (OPM), and one instructional design firm that was outsourced by the OPM. This case study exposes the factors that influence and do not influence on faculty to implement change when they work with instructional designers in this OPM-University partnership model. It exposes the impact on faculty to change their teaching design practices as they work to develop their courses with the instructional designers in the OPM-University partnership.

There is a literature gap on how faculty pedagogical practices in online course development impacts their approaches to teaching design in the OPM University Business Model. This research studies the changes faculties undergo in their knowledge and understanding of teaching practices when they opt to participate in working in an OPM Model with outsourced ID services. The focus is to study how online course development impacts faculty, specifically in relation to their pedagogical knowledge and approach to teaching design. The study examines how the relationship between a research university and an OPM provider impacts faculty approaches to teaching and learning practices. No studies have shown how the instructional designers provided by these OPMs work with faculty to motivate for a change in their teaching behavior. A gap exists in the literature around how faculty interact with such IDs provided by OPMs; and what impact it has in their teaching design, and their pedagogical knowledge and development. This study can help faculty and instructional designers on best practices and preparation in the context of faculty development before getting into this kind of a partnership to build new online programs.

The case study is rendered through the lens of Engeström's (1999) Activity Theory. The Activity Theory framework is a descriptive meta-theory rather than a predictive theory (Engeström, 2000). Analyzing human activity should not only involve examining the kinds of activities people engage in but also who is engaging in that activity, what their goals and intentions are, what objects or products result from the activity, the rules, and 
norms that circumscribe that activity, and also the larger community in which the activity occurs. The most appropriate unit of analysis in a system is 'activity' (Jonassen and Murphy, 1999). In this paper, the activity is the instructional design process within the context of developing higher education online programs. No other studies in this area have used Activity Theory for analysis.

\section{Literature Review}

\subsection{Instructional designers and the instructional design process in higher education}

Instructional Designers (IDs) are professionals who support faculty in colleges and universities in the development of online courses through training and consultations (You, 2010; Chittur, 2010). Instructional Design is "a collection of theories and models helping to understand and apply instructional methods that favor learning. Instructional Design as a method or a process helps produce plans and models describing the organization of learning and teaching activities, resources and actors' involvement that compose an Instructional System or a Learning Environment" (Paquette, 2014, p. 661) IDs are familiar with technological features and learning processes of online course design, and can encourage and provide training for their use and adoption. Most faculty seek to work with IDs for technical support and help (You, 2010; Chittur, 2018). Faculty and administrators sometimes think of IDs as technologists and learning management system specialists; however, they are experts in learning design and can play an important role in the design process to advocate an appropriate mix and sequence of student-centered activities in the online course being developed (Chittur, 2018). Compared to the traditional face-to-face teaching model, online education has generated some clear indicators of quality that place students at the center of instruction (Li and Irby, 2008; Chittur, 2018). Chaney et al.'s (2009) research reveals the findings of several principles of instructional support for both faculty and students (see Table 1).

Table 1: Common Quality Indicators of Distance Education Identified in the Literature

\begin{tabular}{ll}
\hline Student-teacher interaction & Active learning techniques \\
Prompt Feedback & Respect diverse ways of learning \\
Student support services & Faculty support services \\
Program evaluation and assessment & $\begin{array}{l}\text { Strong rationale for distance education that correlates to the } \\
\text { mission of the institution }\end{array}$ \\
& $\begin{array}{l}\text { Appropriate tools and media } \\
\text { Reliability of technology }\end{array}$ \\
$\begin{array}{l}\text { Documented technology plan to ensure quality } \\
\text { Institutional support and institutional resources }\end{array}$ & $\begin{array}{l}\text { Implementation of guidelines for course development and } \\
\text { review of instructional materials }\end{array}$ \\
Course structure guidelines &
\end{tabular}

Source: Chaney et al. (2009)

Use of IDs in converting courses into an online format may cause professors to rethink their roles as teachers and maximize student learning. With the help of IDs, faculty will find themselves shifting focus to learning objectives and designing activities that can help students master those learning objectives (Chittur, 2018).

IDs operate within a community of practice and work with instructors, technologists, academic staff, and other administrative staff in their institution. IDs play a very important role in creating a change among faculty and motivating faculty to implement good teaching design. They should be comfortable in motivating the faculty and bringing a change to help faculty rethink on their knowledge of pedagogy and teaching practice when the interactions between them are going well (Pan et al., 2003).

\subsection{Instructional Designer and Subject Matter Expert (Faculty) Interaction}

Instructional designers require proper interpersonal and communication skills to effectively manage interactions with Subject Matter Experts (SMEs). Successful IDs are those who have collaborative skills to work with faculty and create an atmosphere of mutual respect (Armstrong and Sherman, 1988; Lin and Jacobs, 2008; Chittur, 2018). IDs build rapport with faculty by developing a sense of respect for the professor's teaching style and by limiting the number of suggestions to improve the course design. IDs communication should be managed in a way that the professor or faculty does not feel micromanaged (Chittur, 2018). IDs should not hold themselves out as experts of content matter (Pan et al., 2003; Barczyk, Buckenmeyer, and Feldman, 2010). IDs should be careful to hold themselves as experts of design and not experts of content matter and should also find a balance between their roles as faculty support and as a design expert (Pan et al., 2003; Barczyk, Buckenmeyer, and Feldman, 2010). 
The relationship between an ID and a faculty member is dependent on mutual respect and trust. Professors are more likely to make changes in pedagogy when they anticipate improved learning outcomes (Chittur, 2018). Faculty members believe that their instructional designers need to have a better understanding of their content areas (You, 2010). Experienced faculty who are new to teaching online can get anxious thinking that they may lose their identity as experts and hence resist teaching online (McQuiggan, 2007). IDs are unique and important professionals for an institution who work with faculty and assist them through the process of personal and professional transformation (Campbell, Schwier, and Kenny, 2005; Campbell, 2014; Chittur, 2018).

At times, the interactions between the ID and the faculty member can be difficult and problematic. This can happen especially when the ID tries to emphasize and recommend structure, but the faculty member is focused and used to handling the class session flow through personality and on-the-spot decision-making (Russell, 2015). The relationship between ID and SME is dependent on the strength of their trust in one another (Pan et al., 2003). To succeed, IDs sometimes may need to suppress their own egos to develop positive relationships with faculty (Pan et al., 2003).

\subsection{Online Program Management (OPM) Providers}

Some higher educational administrators outsource the development of their online programs to third-party vendors (Springer, 2018; Powers, 2019; Farakish, Jaggars, and Fay, 2020). These third-party vendors are known as 'Online Program Management' (OPM) providers (Springer, 2018). Universities need a substantial financial investment to develop their online programs internally (Springer, 2018). OPM providers are for-profit companies that invest some or all of the necessary capital up front to create the infrastructure for an online program, and also provide various services related to online program management for partnering with a college or university in exchange for a percentage of the revenue generated from the program (Springer, 2018; Schmoyer, 2020). These OPM providers offer help in four core service areas (Springer, 2018; Powers, 2019; Schmoyer, 2020).).:

1. market/lead generation

2. enrollment management

3. student services

4. course development and delivery

According to Springer (2018),

The OPM provider recruits students to the online program, provides training and support to faculty and students, provides technological expertise, offers academic advising services to the students until graduation, and collaborates with the faculty from the university or college to convert on-campus courses to the online environment. The vendor may also develop marketing strategies to promote the growth of the online program and further the university's brand, and it may help secure regulatory approvals related to online education. (pp. 1-2)

A partnership between a university and an OPM provider is a form of higher education outsourcing (Springer, 2018) and is a business relationship between the university (or college) and the OPM provider.

Colleges and universities need to design and launch higher quality online courses (Riter, 2017; Powers, 2019; Farakish, Jaggars, and Fay, 2020). For these universities and colleges, building high-quality offerings and getting thoughtful instructional design support for their institution's faculty from OPM providers is most important (InsideHigherEd.com, 2019; ; Powers, 2019; Schmoyer, 2020). There is a need by most of these higher educational institutions to get selected services on an a-la-carte basis and pay a fee for that service instead of going with the revenue-sharing bundle or package (Riter, 2017; Powers, 2019; Farakish, Jaggars, and Fay, 2020). Most OPM providers do not have economic sources or expertise to tailor the instructional design for a particular institution, program, or course. Lack of budget, staff, resources, and familiarity with technology creates operational challenges that make outsourcing the development of online courses and programs to OPMs very appealing. However, most of these OPMs maintain only a small number of instructional design staff and place the main duties and responsibilities of the work on an institution's faculty (Riter, 2017; InsideHigherEd.com, 2019; Powers, 2019; Schmoyer, 2020). Most OPM providers do not invest in instructional design because the underlying economic arrangement does not reward or benefit them by tailoring or suiting their approach to a particular college or university (InsideHigherEd.com, 2019). 


\section{Method}

This research follows a qualitative approach using an interpretive case study to help understand the social and cultural contexts within which people live and work. This study focuses on understanding the individuals and organizations involved in instructional design. Human decisions and actions can only be understood in context, and the context helps researchers 'explain' why someone acted as they did (Myers, 2013). The researcher carried out detailed analyses of the decisions and actions taken by faculty within the context of a university and its business relationship with an OPM provider.

\subsection{Sources of Data}

This case study included a private research university (herein called RU or R University) that had recently joined a partnership with an Online Program Management Provider (OPM) to develop and offer online Master's degree programs. The name of the university and the type of online programs, and the name of the OPM provider have been removed to maintain anonymity.

Faculty scheduled to teach in the Fall semester co-developed courses with the assistance of an instructional design firm and a media production firm (outsourced by OPM). These faculty members began receiving training from Faculty Support Services (in-house) provided by OPM. Administrative and technical staff at RU worked with OPM to integrate learning management and student management systems.

\subsection{Activity Theory}

Activity Theory (AT) was used as a framework to describe and analyze the entire work/activity system that involved the RU faculty and community, and OPM. Activity Theory is an umbrella term for a range of social science theories and research originating from Soviet psychologists Lev Vygotsky, Alexei Leont'ev, and Sergei Rubinstein (Cole and Engeström, 1993). Activity Theory is specifically useful in qualitative research methodologies (e.g., ethnography, case study) in providing a method for analyzing and understanding a phenomenon, finding patterns, and making inferences across interactions, and describing and presenting phenomena through a built-in language and rhetoric. Activity Theory offers an external perspective on human practices (Arnseth, 2008). An activity cannot be understood or analyzed outside the context of which it occurs (Jonassen and Murphy, 1999). Analyzing human activity should not only involve examining the kinds of activities people engage in but also who is engaging in that activity, what their goals and intentions are, what objects or products result from the activity, the rules and norms that circumscribe that activity, and the larger community in which the activity occurs. These are all parts of the activity system (Jonassen and Murphy, 1999).

Activity System. The most appropriate unit of analysis in a system is 'activity' (Jonassen and Murphy, 1999). The components of any activity are organized into activity systems (see Figure 1). The production of any activity involves the subject, the object of the activity, the tools (mediating artifacts) that are used in the activity and the actions and operations that affect an outcome (Jonassen and Murphy, 1999). The subject of any activity is the individual involved in the activity or the group of actors engaged in the activity. The object of the activity is the physical or mental product that is created. The object is acted on by the subject and is a representation of the intention that motivates the activity. Tools can be anything that will be used in the transformation of this process. The use of specific kinds of tools will shape the way people (or subjects) act and think. The tools alter the activity and are in turn altered by the activity (Jonassen and Murphy, 1999).

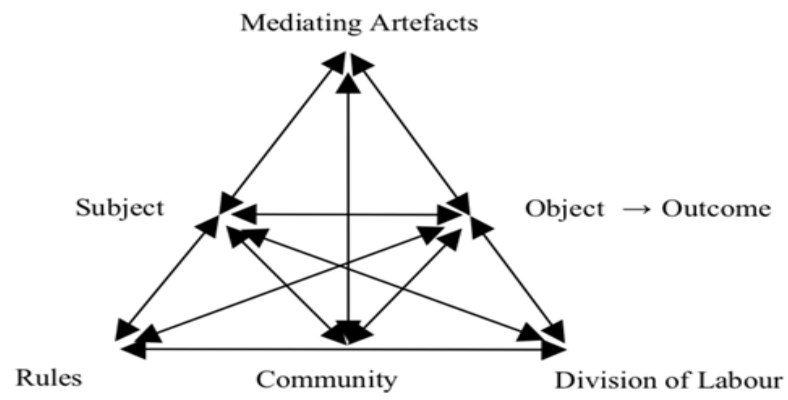

Figure 1: Engeström's (1999) model of an activity system 
The AT model includes the following vertices moving in a clockwise rotation from mid-left: subject, mediating artefacts (tools), object, division of labor (roles) that influence the subject, community, and rules (Bradford, Kehrwald, and Dinmore, 2011). This model sets the actor and target action (or behavior) within the frame of the key factors having an influence on the actor and target action. Adjusting the model to the case of faculty and their teaching practices when launching online programs via a business relationship, the faculty is the subject with teaching as an object of active learning with an outcome target of new competencies. Teaching here implies anything related to the practice of teaching. It can also be improvements or new skills learned by the faculty member. Examples include a new approach to curriculum design, multimedia (audio or video) instruction, discussion forums, scaffolding, etc. The influences on the instructional process include current faculty roles, such as teaching and/or research, marketing, admissions, recruiting, leads, senior administrative officers, senior managerial staff, program leads, OPM managerial staff, the IDF (Instructional Design Firm) managerial staff, learning leads, and Instructional Designers working to support the object target outcomes (Bradford, Kehrwald, and Dinmore, 2011). Fellow faculty are part of the RU community. The community also includes technical and administrative staff from the RU. Fellow faculty (colleagues of faculty as actors) also impact other faculties as actors in the community section in this model. The community section also includes the students at RU. Students are part of the community in this model because the faculty provides educational experiences for their students. Policies, contracts, goals, quotas, deadlines, milestones, reviews, and evaluations are the rules that influence the faculty approach to teaching design. Finally, ICTs (Information and Communication Technologies), an LMS (Learning Management System), synchronous technologies, and other software that are used are the main tools to support online teaching for faculty and help them design pedagogy. All kinds of technologies like data management integrations and other support systems from RU, the OPM provider and the IDF are also part of the 'Tools' section, and impact faculty approaches to teaching design. In this framework, pedagogical knowledge and development gained by faculty can be considered as a mediator to reach the object by the actor (impact on teaching design by faculty). The resulting model incorporates the key actors playing a role to make an impact on faculty approaches to teaching design.

Activity Theory is a powerful framework for analyzing how faculty change their approaches to teaching design when they experience all the activities related to developing and launching online programs with an OPM provider. AT is also very useful because its assumptions are consonant with those that impact teaching design, faculty training and support, instructional designer and faculty interaction, pressure from the college community, student feedback and evaluation, faculty and technology interaction, policies, and contracts with regards to R University and the OPM provider, and the amount of time involved in designing online courses, and peer pressure (competing with other faculty members).

According to Bradford, Kehrwald, and Dinmore (2011), activity theory can be used as a framework for an organization to self-evaluate its "Technology-enhanced learning" (TEL) or online learning practices. "The purpose of such a framework is to permit organizations a method by which they may examine their support for sustained innovation" (Bradford, Kehrwald, and Dinmore, 2011, p. 163). AT will support analysis in this case study by observing faculty and the community, roles, tools, and rules all the way from the start when faculty received training on course development and shifted to some on-ground teaching, and how the partnership between the two organizations managed the process. See Figure 2. 


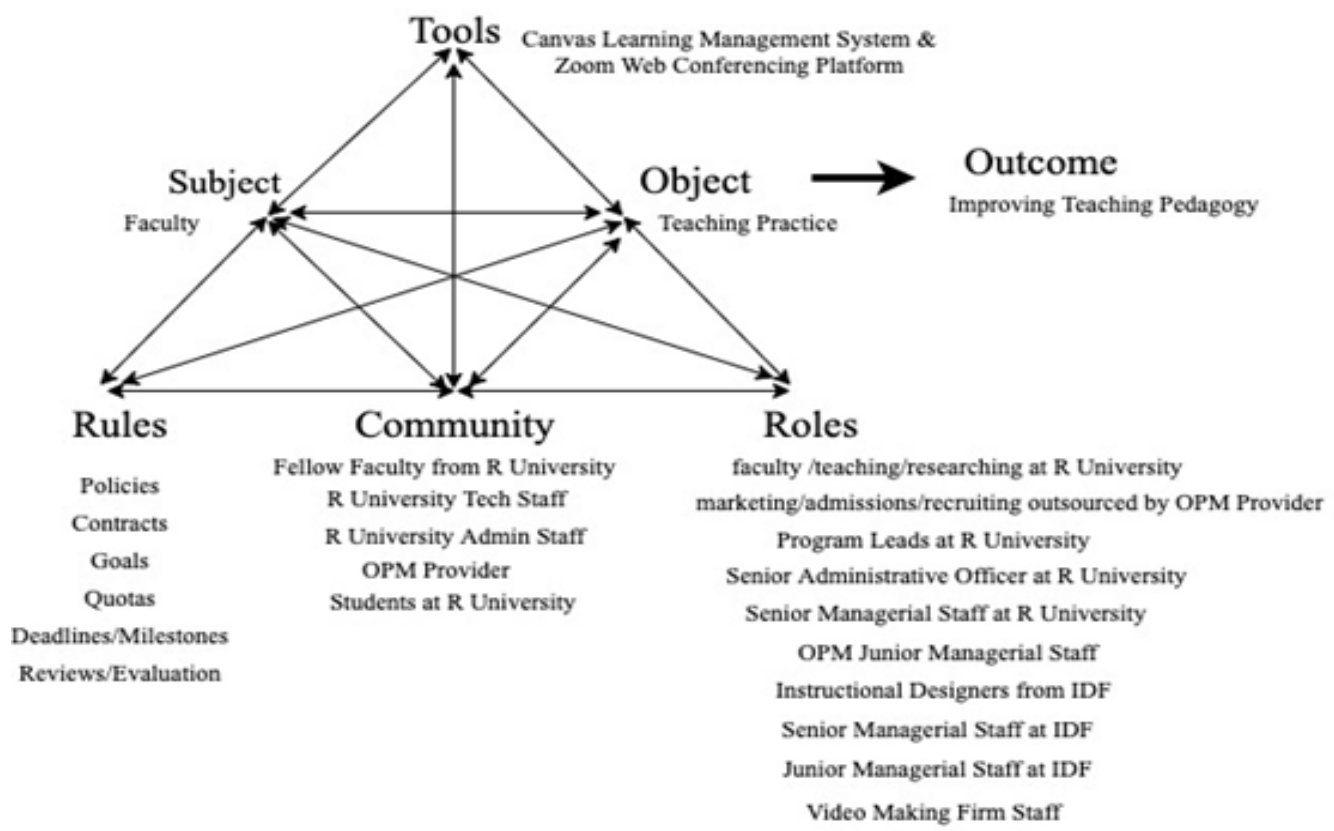

Figure 2: Activity system context for the RU and OPM business partnership

\subsection{Research Design}

The key informants were Research University (RU) faculty members, RU staff, OPM staff, and instructional designers from the outsourced Instructional Design Firm (IDF). The author had professional contact with one of the Program Leads of the online programs at R University who acted as gatekeeper. The Program Lead contacted the upper-level management of R University and the OPM provider managers to get the required permissions and formalize the study. The upper-level management of $R$ University and the OPM provider managers granted permission because they felt that this study was important to understand how the relationship affects faculty professional development. The Program Lead sent out an email to all faculty who were going to participate in developing or teaching online courses and was able to motivate all colleagues to participate. Fifteen faculty members were interviewed. The researcher also interviewed one senior manager and two junior managers from the OPM provider who were overseeing the instructional design process to participate. The researcher interviewed the junior instructional design manager and four instructional designers from the instructional design firm.

\subsubsection{Data collection procedure}

Interviews, participant observation, and documents were the primary sources of data collection. Meetings between the faculty and instructional-opm staff were observed. Canvas course blueprints and university web pages were used as documents to verify data. The study was considered as "Exempt" by the RU Institutional Review Board.

\subsubsection{Data analysi}

The objectives of this study were met through a rigorous interpretive analysis process guided by Activity Theory. The first step involved the preparation of the data for analysis and becoming familiar with the data. The recorded interviews were transcribed. Analysis of the interview data was concurrent with the on-going data gathering. After reading and reviewing the interviews several times, the researcher could begin to identify patterns. During the initial phase and the middle phase of the analysis, the researcher communicated with many participants to follow up on additional data as more patterns and insights were found.

The initial coding was done using Strauss and Corbin's (1994) coding method. An effort was made to uncover prominent themes in the experiences of faculty as well as how they are being influenced by each 'role', 'rule', 'technical tool', and everyone in the 'community.' Looking at each of the vertices of the Activity Theory model, the researcher uncovered prominent themes in the project management process during this launch of online programs. Activity Theory complements how to explain the dynamic of the social and collaborative work environment. 
For this study, data triangulation was used for the instructional design process and some parts of the instructional delivery process of the online programs. Participation observation data from the ID-faculty meetings along with interviews of faculty, instructional designers from the instructional design firm and OPM junior managers were used to understand the instructional design process that took place. Along with observing meetings and participant interviews, Canvas course blueprints were also used to verify some data related to the pedagogical strategies implemented via the influence of the instructional design process. The university website and university-OPM agreement contract was also used to understand a bigger picture.

\section{Results}

Four themes emerged from this study after interviewing faculty and observing the instructional design process. On the following activity system context diagrams, for each theme arrow 1 shows that faculty are bound to the ID staff by a contract (Rules) between RU and the OPM which specifies that faculty receive stipends for developing online courses. The ID staff are bound by the same contract, as represented by arrow 3 . Conflicts between faculty and "IDF + OPM" staff are represented by other uni- and bi-directional arrows.

The nodes on the Activity Theory mediational triangle represent relationships between sources of influence on the subject and the object and the outcome produced. Sometimes in these themes emerged, the relationships could be said to be in harmony ("equilibrium"), and other times, they are not, such as when roles are not clearly defined, rules are poor or missing, the community has an opposing view towards the subject and the activity to be produced (Engstrom, 1987). At times when the relationships are not in harmony, it can be said that the relationship is in tension and such tension might not be released until some correction is made (Engstrom, 1987). At times the tension could be one-directional, where perhaps the subject is not knowledgeable about rules, roles, the community's influence, or how to use mediating tools, or it could be that the tension comes from the other way when rules restrict action, roles are not designed to accommodate the situation, the community is expressing a course of action counter to what the subject believes must be done, or there might not be an account set up in the system (Engstrom, 1987). Bi-directional tension occurs when the tension flows both ways if there is a situation of mutual conflict (Engstrom, 1987). All the themes described below do not apply to all faculty but some or most of the faculty.

\subsection{Theme 1: Faculty consider the online teaching initiative to be beneficial for their university and are motivated to participate}

Faculty were selected to design online courses that were part of their online programs, based on their background and expertise in teaching these courses. Faculty who were in permanent positions at RU and who had been working at RU for a very long time considered this opportunity to teach online as beneficial to their university as a way to generate additional revenue. They considered it necessary and important to meet student demands, and to be competitive in the growing online market.

As shown in Figure 3, the faculty (the subjects) care about teaching online (the object) as they consider it to be beneficial for their school (the motivation, as represented by the dotted circle line). In this figure, everything is in equilibrium in this activity system. There is motivation by faculty to participate in this process and that is to benefit their school to improve their student enrollment, be competitive in the marketplace, and implement new technical innovations through online learning. 


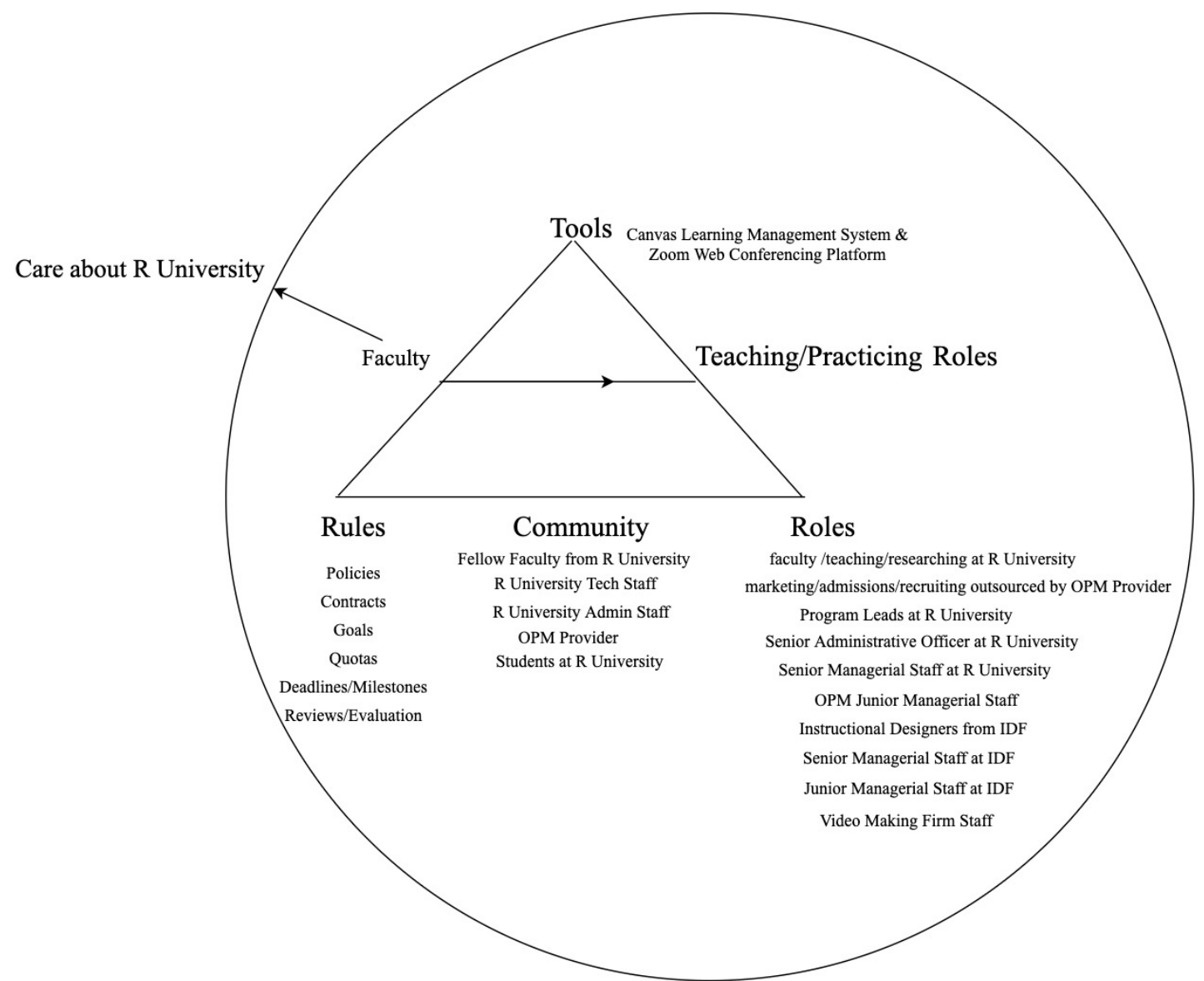

Figure 3: Activity System Context for Theme 1

For one faculty, it is meeting the future of academia:

First of all, it's attractive for me because this is the, we're in the 21st century and this is the future of our students are going to be. ... So, I think this is the future of academia.

Some of the faculty want to increase their school's student enrollment.

Yeah. There is definitely there is a demand

One of the reasons was the high demand if this degree program is in an online format. ... We had a lot of students coming saying, you know is there any way we participate in your training in an online format.

Some faculty want to help generate revenue for their schools.

I think it is probably necessary because there is you know so much that ... so much of higher ed is heading in that direction.

Some faculty want to catch up with the market demands and compete with other universities.

It is adjusting ourselves to market changes and offering programs that students would like to consume today that people work remotely.

I think this is a really good opportunity for the university and help grow our enrollment.

\subsection{Theme 2: Some faculty have a difference of opinion on the ideas and guidance on pedagogy provided from the ID staff and were unwilling to change}

Figure 4 shows the flow of tension between faculty and ID staff is bi-directional. The ID staff (OPM+IDF-->Roles) is unable to motivate some faculty (Actors) to use effective (Pearce and Husbands, 2012) pedagogy leading to mutual conflict, hence arrow 2 is bi-directional. Some faculty are unwilling to accept the suggestions from ID staff and hence do not change their pedagogy, but some faculty adjust to the change in pedagogy of their course design as suggested by the ID staff. Many faculty also considered the ideas and suggestions provided by the ID staff were undergraduate level and that they do not understand graduate level education. Conflicts also arose when their ID did not have the subject matter background that the faculty was teaching. 


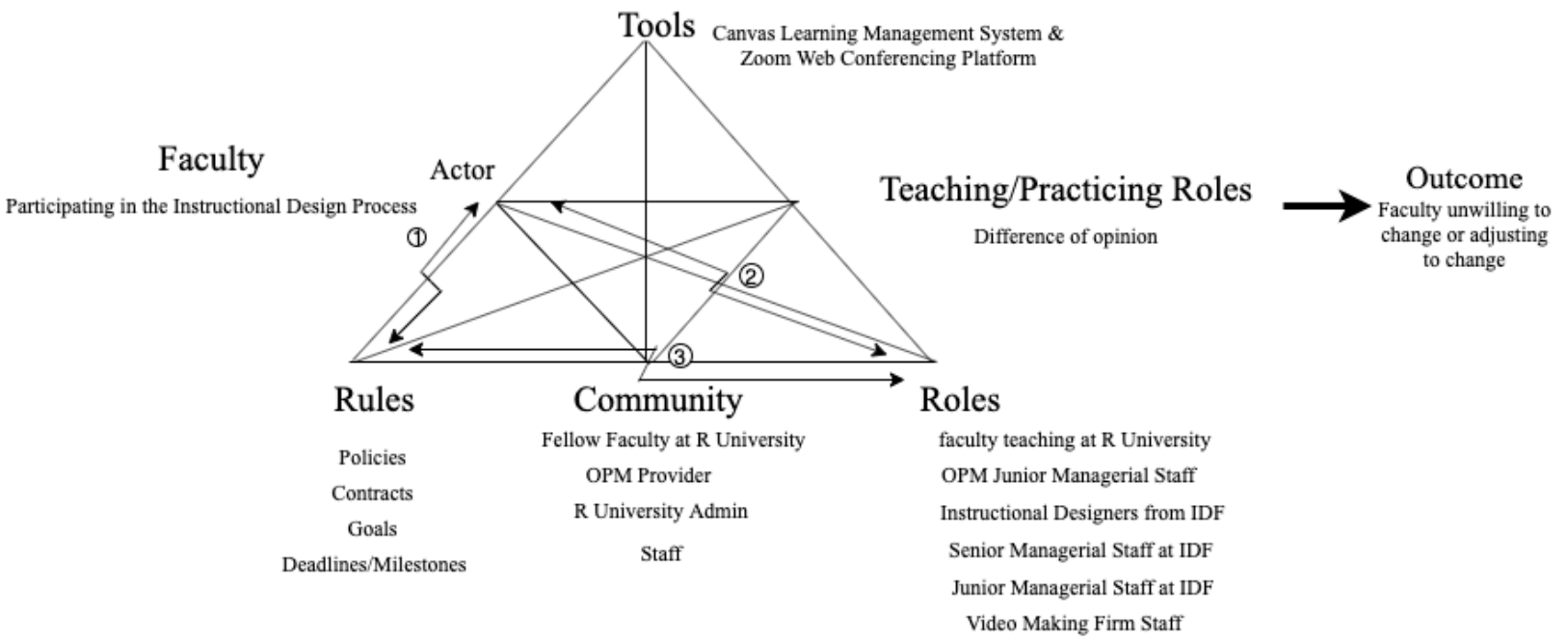

Figure 4: Activity System Context for Theme 2

For example, in designing a course, one of the faculty was not impressed with the instructional design ideas and had a difference of opinion and disagreements with their ID.

This is a graduate level course. It's not simple readings.

The ID who worked with this faculty stated that this faculty's personality is rigid and is not willing to change. This Faculty has a very conservative point of view when it comes to how (he or she) would teach and while (he or she) was open and listened to what we had to say about ...... would be surprised if I saw that would change his or her teaching considerably.

In designing for a course, another Faculty also faced a difference of opinion but adjusted to the suggestions provided by his/her ID.

So they want to make sure that if I say a reading, the reading has been provided properly. If there is something due, they want to make sure that instructions and everything are clear. Now again, as I said, I feel like that's a little bit for more undergraduate students, little bit more hand holding. But I still thought that it wasn't a bad idea.

This faculty also had a difference of opinion regarding rubrics and exam solutions.

I am not a big Rubrics person. But they wanted to have a Rubric for everything. That was created. They created it. I had some for my projects and assignments, so they used those. The other thing that is still pending and the faculty who is teaching this course and I do not like is that they want solutions for midterm and final exams and you know in a graduate class specially not all questions are multiple choice and there are subjective questions. I don't want to create solutions. But they are asking me too.

The ID working with this faculty responded for this faculty as:

It's really how this faculty understands that you know we weren't just doing this just to make work. There really were some sound pedagogies behind making some choices that we had to make in the class.

Another Faculty was not supportive of an idea of an assignment provided by the ID he or she was working with. First tangible example is ID had talked about a quiz every week and to make sure before the students came into the live session they could pass a quiz on the readings and I pushed for having them answer discussion questions amongst themselves you know on this listserv model that we have and have the TA moderate the discussion.

Another example that this faculty also mentioned is:

The ID also pushed us to you know to develop what I would see as a detailed point system for all activities and so forth and you know that's not the way most of us teach graduate level education and sort of the view was that online students are not going to do readings and do work if you don't have points attached to each thing and so far I am finding that to be not very helpful. 
The ID responded to working with this faculty as:

In some cases, this faculty was open to trying new things. At other times, this Faculty wanted to stick with what (he or she) knew worked well from past experience.

The ID staff tried to motivate and push for implementing multimedia videos in courses to faculty but many faculty did not want to create videos because they did not see the value. They thought of these videos as too much like undergraduate level pedagogical elements and not suited to graduate level education. One of the Faculty considered the videos samples to be very basic too undergraduate level. This faculty adds:

For example, how do cellular phones work. You know I had slides but if that would have been video that would be helpful. Some of those were done, but at the end of the day what IDF was telling me and many others, I felt like they did not truly understand graduate school education.

One faculty mentioned that videos do not suit their teaching style and they do not really teach using videos in their residential classes. Another faculty mentioned that they were looking for some different pedagogical strategies and ideas for their course other than creating videos that seemed too undergraduate level. The faculty wanted students to do work and perform active learning instead of just presenting information via videos. Faculty thought the material too complex to help students understand how to make decisions by watching videos.

One of the faculty assumed that students at the graduate level can get course content easily without multimedia and through all the instructional materials provided. This faculty said:

The multimedia stuff. Our students don't need that. They get it. We have good clear description of what they need to do. They are graduate students.

Another faculty felt that videos have their own place. This faculty was in conflict with the ID regarding the location in the course they were asking to use videos.

So, you know there is a place for videos. But we had a constant fight of struggling with saying, you know the point of [having] videos for their own sake [is not] any more than to have PowerPoint [slides] for their own sake.

Some faculty were frustrated because their IDs did not have the background and knowledge in their subject matter for which they were going to teach online. They preferred that their ID also had knowledge in the subject they were teaching. They considered this problem to be more time-consuming to complete the course development process. For one faculty, this was a main problem for late completion.

You know, the ID had essentially zero understanding of the content of the course, you know, which I can appreciate. Because, it's course $[A B C]$ so it's not, you know, you have to have some background. If we talk about course $A B C$ topics $[X, Y, Z]$, if you don't understand what that is, how are you going to develop a course.... they're not going to happen. And that was the main problem.

For two faculties of one of the programs, their matched ID knew their subject matter. Their ID studied the same major. One of these faculty thought that everything worked well with their ID because of the ID's knowledge of the subject matter and did not work for some other faculty they knew due to the lack of those ID's subject matter knowledge.

We had a designer that was very good who knew the subject matter and not just how to do instructional design. The ID was a major [A] student and knew about our major and overall [what] our experience was. You know, exceptional; and we really had a good experience. But in talking with other faculty, they had, you know, different experiences. And I come away realizing that, you know, that most things are in the chemistry between the designer and faculty shared knowledge base. You know that really made a difference. 


\subsection{Theme 3: Faculty clearly think about their students and take into consideration ideas only that benefit their students during the ID process}

Figure 5 represents flow of tension is one-directional (arrows 4 and 5) as faculty only consider ideas from the IDs that benefit their students through their course design. The ID staff from OPM and IDF influenced the faculty (arrow 4) to design their course in the best favor of their students. When the ID staff provided their design suggestions, faculty considered whether the suggestions would be effective for their students. Therefore, the students influence the faculty to make design decisions (as represented in arrow 3). The impact on faculty pedagogical knowledge is from analyzing and implementing ideas that help their students achieve the most effective learning experience (arrow 5). The outcome is that ID staff maintain mutual respect and do what faculty prefer to do for these students.

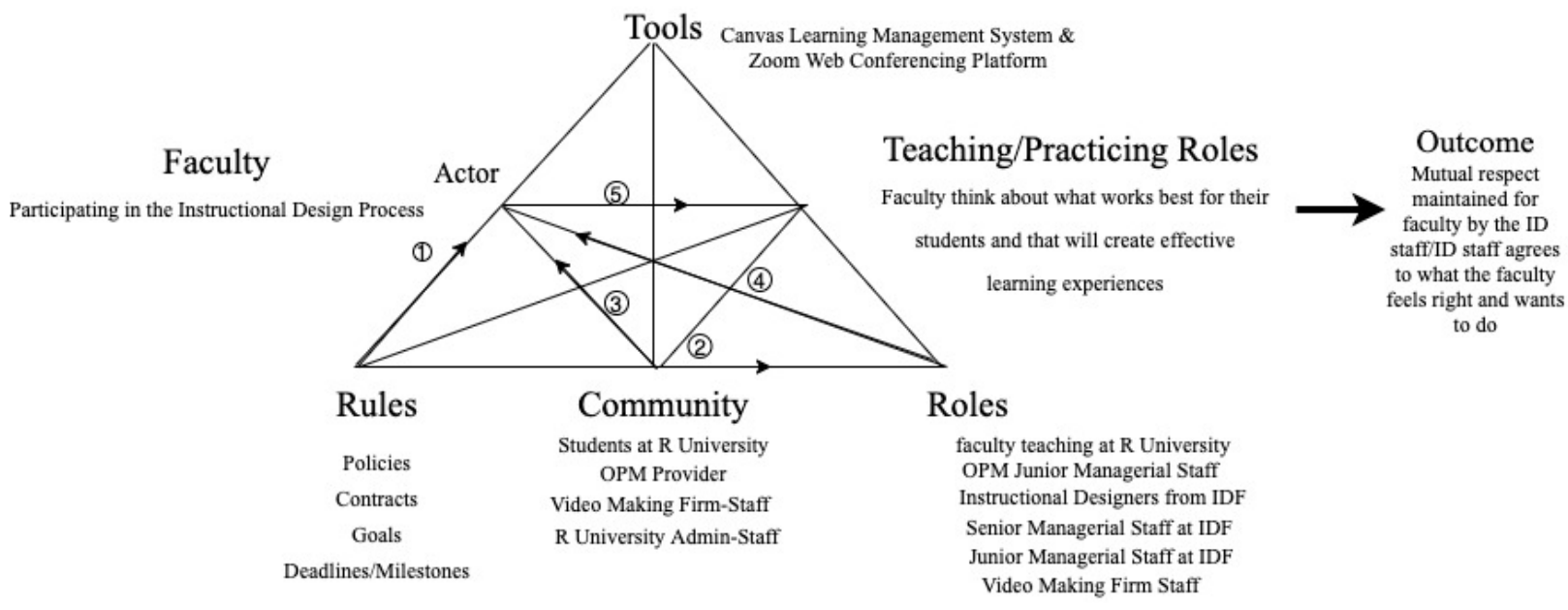

Figure 5: Activity System Context for Theme 3

For example, one of the faculty did not consider multimedia ideas but did consider the idea of having knowledge checks:

I think we were thinking about what the students are more capable of doing. Sometimes, they say no it's fine. The multimedia stuff. Our students don't need that. They get it. We have good clear description of what they need to do. That was a conflict of interest. Second was knowledge checks. At first I thought do they really need that. But then I realized it can help me structure the live sessions.

One faculty did not like the idea of having a quiz every week but instead considered having a discussion: A tangible example is this ID had talked about a quiz every week and to make sure before the students came into the live session they could pass a quiz on the readings and [what] I pushed for them to do is answer discussion questions amongst themselves you know on this listserv model that we have and have the TA moderate the discussion. And that's a clear example of us going in that direction.

One faculty did not consider the suggestion of gamification techniques from their ID:

You know and one of the things that I think this ID did not push, which I kind of appreciate it, but [what] this ID certainly made available were some of the aspects of gamification. Right, like how to make it like a game, and you know that's just I have personal preference where I don't think that's really appropriate for this [level]. And I told this ID that pretty much straightforward upfront and this ID was pretty much okay with that.

\subsection{Theme 4: Technical tools fascinate faculty to teach online}

Figure 6 shows the flow of tension from the IDs from OPM and IDF to the faculty is one-directional (arrow 4) because faculty were excited to use technical tools and see how the pedagogical strategies from face-to-face class sessions can be explored online. The IDs influenced the faculty by providing suggestions on implementing pedagogical strategies that can be applied by using technologies. 


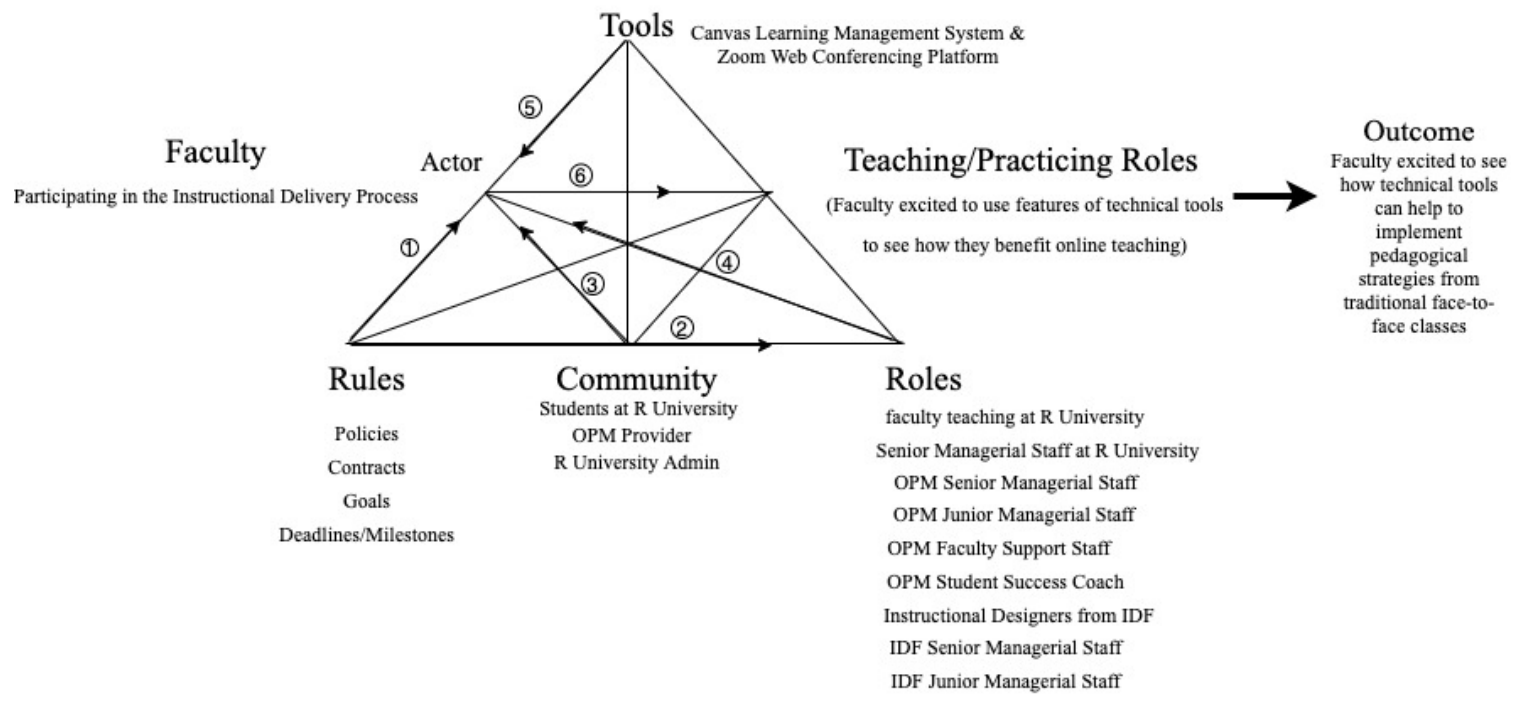

Figure 6: Activity System Context for Theme 4

When the ID staff provided their suggestions of pedagogy, many faculty thought about how the technical tool can help them replicate what they did in their traditional face-to-face classes in their live Zoom session. Thus, the technical tools influenced the faculty (arrow 5). The students influence the faculty (actor) to think and imagine and hence plan for such activities (arrow 3). Faculty were motivated to apply their pedagogical knowledge and features of technical tools to benefit student learning through online teaching (arrow 6). The above-noted one-directional tensions in the activity system combined to enable faculty to see how technical tools could be applied and would help them implement pedagogical strategies from traditional face-to-face teaching.

One faculty found Canvas LMS to be beneficial as it makes assignment submissions more effective. Technology provides evidence on when the assignment was submitted by the students. This faculty liked the grouping feature and was also excited about the whiteboard feature in Zoom, although they were concerned about how to use it.

I really like, in general, I like in Canvas that submissions are clear and there is a day you know. You don't have to deal with lots of papers. You know people sometimes tell you that they have submitted but cannot find it as evidence as it is. That's probably going to be general for all electronic tools. But Zoom, I kind of like the grouping feature in it. I was excited about the whiteboard feature.

For one faculty, the modules feature in Canvas worked well. This faculty now thinks having modules is a better way to teach.

I think the Modules. It is something that I don't do in my physical classes. Because I prefer to keep it simple by going into files and creating folders. So I create slides for week 1, week 2. But I think if I create modules for each session and provide all the materials in the modules that might be a better way to teach.

One of the faculty was excited to see how the grouping feature worked in Zoom. They really wanted to see how the grouping ability done in the traditional format can be done online the same way.

I think I'm really excited to see how that um, uh, how does a group feature in Zoom going to work out? And so the breakout room or breakout group or whatever they call it, Zoom. Um, so I'm quite curious about how, how well that is going to replicate what we can do on the ground.

\section{Discussion}

Activity Theory was utilized to help understand the social and cultural perspective of how faculty are influenced (Salomon, 2003). Faculty came in contact with the technical tools, the R University community, OPM staff, IDF staff and Video Making Firm (VMF) staff; and reacted according to their past knowledge and experiences, as mediated by the tools, and social and cultural interactions with the individuals from all the involved organizations (Salomon, 2003). The faculty in this business relationship are defined by their past experiences and knowledge of teaching and teaching online, assumptions about what effective teaching is, assumptions 
about what an instructional designer does, interaction with the technical tools, interaction with the R University and OPM environments, their personality, intentions to participate in this process, attitudes towards this process, technology as well as pedagogy, and learning mindset (Salomon, 2003).

Thus, based on this study there is not one set answer or a set pattern on the instructional design process that influences Faculty in this OPM-University business model. Because every faculty has their own reasons for how they design and teach courses and instructional designers need to know these differences before they begin their partnership. Faculty were got into this process first. Faculties who have been with R University for a long time want to grow enrollment and support the university initiatives. When they get into the ID process, they face many conflicts for many different scenarios. Most of the ideas provided by the ID staff are considered a better fit for undergraduate education and not graduate level. Many pedagogical suggestions were not taken by some faculty. Some faculty took suggestions only that would benefit their students. Some faculty adjusted to the ID staff suggestions. Many faculties who did not use technical tools often or who did not teach online before were excited to see how these tools work for teaching strategies online.

Thus, all faculty come into this process or are brought into this process with:

- Different knowledge and thinking about pedagogy

- Different assumptions about pedagogy

- Different intentions to participate in the process

- Different attitudes about technology as well as pedagogy

- Different past experiences with teaching face-to-face or online

- $\quad$ Different personalities.

The faculty had their own set of assumptions on teaching. None of these assumptions were clarified at the start of the ID process. They assumed some strategies worked only for undergraduate level and not graduate level. They also assumed only some pedagogical strategies will work for their students and some will not and only be implemented those that they thought would work for their students. They also assumed that their ID needs to have their subject matter background. ID is a professional who is an expert in learning design and must maintain a balance between being a content expert and a learning design expert so that the faculty does not feels micromanaged (Halupa, 2019). Based on the literature review IDs are experts in the area of learning design and can play an important role in the design process to advocate an appropriate mix and sequence of studentcentered activities in the online course being developed (Chittur, 2018). ID's bring expertise on how people learn and work with the subject matter expert to design for the most effective learning experience. However, in this study, some faculty were concerned with the content knowledge of the ID's they were working with. Their experiences seem to be frustrating and more time consuming because they thought that their ID did not have their subject matter expertise. IDs are matched to a faculty member based on their background and interests. These assumptions by faculty created tension in the minds of faculty about the ID process and they were frustrated that they had to spend more time because of the lack of their IDs' subject matter knowledge by their ID.

Thus, the most important of all the factors is their current pedagogy knowledge as defined by:

- what they know about their own teaching,

- how it differs with best teaching practices,

- what they really know about their assumptions of teaching,

- how aware are they of their own teaching,

- what they consider as good pedagogy or not so good pedagogy, and

- what their viewpoint is on how students learn and what is best for them.

These are the most important factors.

\section{Conclusion}

Thus, faculty's own thinking about their teaching plays a very important role for the growth in pedagogical knowledge and development that can be gained from the ID process in the OPM Model. To get the best from the ID process, faculty needs to keep their assumptions aside and try to understand that the ID's suggest implementing strategies that are evidence-based and that have proven to work for effective cognition. Every 
strategy has a sound logical reasoning which the faculty need to understand. Thus, a learning mindset is very important for the faculty to get the most out of this process.

It can be concluded that the Activity Theory framework was very useful to investigate and understand the social and cultural perspective of how faculty interact with different individuals and technical tools involved in an OPM partnership and how this impact on their pedagogical knowledge and development.

\subsection{Implications for Practice}

Faculty should be willing to learn. Especially those faculty who are new to online instruction. Faculty should not be participating just due to the pressure by their upper-level management but because they really want to teach online. Faculty should also be ready to check their own assumptions and knowledge they have about pedagogy. Participating in online course development plays a very important role in their pedagogical knowledge and development.

\subsection{Limitations}

This research is only based on one case study at a research university in the United States. There is a possibility that the interview answers from IDF staff were biased due to the fear of not wanting to give out any information that has a negative impact on their own organization. There were also time constraints as it was not possible to follow the partnership through more than two terms and the programs for this study were only for master's degrees.

\subsection{Further Research}

Faculty in this study commented on the differences between graduate and undergraduate teaching as a point of contention with their IDs. Aspects of faculty knowledge and assumptions about teaching and learning can be further researched, especially regarding their assumptions about distinctions between undergraduate and graduate teaching.

The use of Activity Theory in e-learning practice and research could also be another area for further research. Because Higher Education managers and administrators have significant involvement with online teaching, especially with respect to OPMs, Activity Theory may prove to be a very useful technique to help them analyze and quickly solve problems in online education, for example, problems in relation to faculty schedule, instructional designers and subject matter knowledge, faculty training in pedagogy and technology when getting into online education, etc.

\section{References}

Armstrong, J. B., and Sherman, T. M., 1988. Caveat emptor: How SME's can ensure good ID. Performance + Instruction, 27(4), pp 13-18.

Arnseth, H. C., 2008. Activity theory and situated learning theory: Contrasting views of educational practice. Pedagogy, Culture \& Society, 16(3), pp 289-302.

Barczyk, C., Buckenmeyer, J., and Feldman, L., 2010. Mentoring professors: A model for developing quality online instructors and courses in higher education. International Journal on E-Learning, 9(1), pp 7-26. Available at $<$ https://www.editlib.org/p/29273> [Accessed 27 November 2021]

Bawa, P., 2016. Retention in online Courses: Exploring issues and solutions $-A$ literature

review. SAGE Open. 6 (1), pp 1-11.

Boling, E., Hough, M., Krinsky, H., Saleem, H., and Stevens, M., 2012. Cutting the distance in

distance education: Perspectives on what promotes positive, online learning experiences. The Internet and Higher Education, 15(2), pp 118-126.

Bradford, G., Kehrwald, B. and Dinmore, S., 2011. A framework for evaluating online learning in an ecology of sustainable innovation. In G. Williams, P. Statham, N. Brown and B. Cleland (Eds.), Changing Demands, Changing Directions. Proceedings Ascilite Hobart 2011. pp 162-167.

Breunig, M., 2005. Turning experiential education and critical pedagogy theory into praxis. Journal of Experiential Education, 28(2), pp 106-122.

Cassim, F., 2013, Hands on, Hearts on, Minds on: Design thinking within an education context. International Journal of Art \& Design Education, 32, pp.190-202.

Campbell, K., Schwier, R. A., and Kenny, R. F., 2005. Agency of the instructional designer: Moral coherence and transformative social practice. Australasian Journal of Educational Technology, 21(2), pp 242-262.

Campbell, P. C., 2014. Modifying ADDIE: Incorporating new technologies in library instruction. Public Services Quarterly, 10(2), pp 138-149. 
Chaney, B. H., Eddy, J. M., Dorman, S. M., Glessner, L. L., Green, B. L., and Lara-Alecio, R., 2009. A primer on quality indicators of distance education. Society for Public Health Education, 10(2), pp 222-231.

Chittur, D., 2018. A phenomenological study of professors and instructional designers during online course development leading to enhanced student-centered pedagogy (Doctoral Dissertation). ProQuest Dissertations \& Theses Global. (2035341879). Available at from < http://ccl.idm.oclc.org/login?url=https://search-proquestcom.ccl.idm.oclc.org/docview/2035341879?accountid=10141> [ Accessed November 20, 2020].

Cole, M., and Engeström, Y., 1993. A cultural-historical approach to distributed cognition. In G. Salomon (Ed.), Distributed cognitions: Psychological and educational considerations (1st ed., pp. 1-46) Cambridge University Press.

Crawley, F. E., Fewell, M. D., and Sugar, W. A., 2009. Researcher and researched. Quarterly Review of Distance

Education, 10(2), pp 165-176.

Educause.edu., 2010. Enhancing student learning and retention with blended learning class guides. Educause Review. Availaible at $<$ https://er.educause.edu/articles/2010/12/enhancing-student-learning-and-retention-with-blendedlearning-class-guides $>$ [Accessed February 11, 2019].

Engeström, Y., 1999. Activity theory and transformation. In Y. Engeström, R. Miettinen, and R. Punamaki (Eds.), Perspectives on activity theory (pp. 19-38). Cambridge: Cambridge University Press.

Engestrom, Y., 2000. Activity theory as a framework for analyzing and redesigning work. Ergonomics, 43(7), pp 960-974.

Fain, P., 2020. Interest spikes in short-term, online credentials. Will it be sustained? Available at < https://www.insidehighered.com/news/2020/08/27/interest-spikes-short-term-online-credentials-will-it-besustained> [Accessed August 15, 2021].

Farakish, N., Jaggars, S., and Fay, M., 2020. American Honors: The life and death of a public-private partnership. community college research center at Columbia University Teachers College. Available at $<\underline{\text { https://ccrc.tc.columbia.edu/publications/american-honors-life-death-public-private-partnership.html }>\text { [Accessed }}$ 27 November 2021]

Fetherston, T., 2001. Pedagogical challenges for the World Wide Web. Educational Technology Review, 9(1), pp 25-32.

Fink, L. D., 2013. Creating significant learning experiences: An integrated approach to designing college courses. Second Edition. San Francisco, CA: Jossey-Bass.

Fink, L. D., 2013a. The current status of faculty development internationally. International Journal for the Scholarship of Teaching and Learning, 7(2), pp 1-10.

Gayeski, D. M., 1997. Out -of-the Box instructional design: Moving from assembly-line models to non-linear performance models. Available at <http://www.dgayeski.com/t\&disd.html> [Accessed April 20, 2018]

Halupa, C., 2019. Differentiation of Roles: Instructional Designers and Faculty in the Creation of Online Courses. International Journal of Higher Education, 8(1), pp 55.

Hardy, K., and Bower, B., 2004. Instructional and work life issues for distance learning faculty. New Directions for Community Colleges, 2004(128), pp 47-54. DOI: https://doi.org/10.1002/cc.174

Hone, K. S., and Said, G. R., 2016. Exploring the factors affecting MOOC retention: A survey study. Computers \& Education, 98, pp 157-168.

InsideHigherEd.com., 2017. Easing instructional designer-faculty conflicts | Inside Higher Ed. Available at $<$ https://www.insidehighered.com/digital-learning/article/2017/05/03/easing-conflicts-between-instructionaldesigners-and-faculty> [Accessed December 25, 2020]

InsideHigherEd.com., 2017a. Quashing Tension, Boosting Cooperation | Inside Higher Ed. Available at $<$ https://www.insidehighered.com/digital-learning/article/2017/05/10/roundup-instructional-designers-and-facultyideas-working > [Accessed December 25, 2020]

InsideHigherED.com., 2019. The instructional designer and the OPM conversation | Inside Higher Ed. Available at <https://www.insidehighered.com/blogs/technology-and-learning/instructional-designer-and-opm-conversation> [Accessed February 11, 2019]

Jonassen, D. H., and Rohrer-Murphy, L., 1999. Activity theory as a framework for designing constructivist learning environments. Educational Technology Research and Development, 47(1), 61-79.

$\mathrm{Li}, \mathrm{C}$., and Irby, B., 2008. An overview of online education: Attractiveness, benefits, challenges,

concerns and recommendations. College Student Journal, 42(2), pp 449-458.

Lin, Y., and Jacobs, R. L., 2008. The perceptions of human resource development professionals in Taiwan regarding their working relationships with subject matter experts (SMEs) during the training design process. Human Resource Development International, 11(3), pp 237-252.

McQuiggan, C. A., 2007. The role of faculty development in online teaching potential to question teaching beliefs and assumptions. Online Journal of Distance Learning Administration, 10(3), pp 1-13.

Morris, S. M., and Stommel, J., 2016. Why Online Programs Fail, and 5 Things We Can Do About It. Hybrid Pedagogy. Available at <https://hybridpedagogy.org/why-online-programs-fail-and-5-things-we-can-do-about-it/> [Accessed May 1, 2018]

Myers, M. D., 2013. Qualitative research in business and management. Los Angeles: SAGE.

Oliver, R., 2002. Exploring strategies for online teaching and learning. In L. Foster, B. L.Bower, and L. W. Watson (Eds.), ASHE Reader-Distance education: Teaching and learning in higher education (pp. 249-257). Boston: Pearson Custom.

Pan, C. C., Deets, J., Phillips, W., and Cornell, R., 2003. Pulling tigers' teeth without getting bitten: Instructional designers and faculty. Quarterly Review of Distance Education, 4(3), pp 289-302. 
Paquette, G., 2014. Technology-based instructional design: Evolution and major trends. In D.H. Jonassen (Ed.), Handbook of research on educational communications and technology (pp. 661-671). New York, NY: Springer.

Pearce, J., and Husbands, C., 2012. What makes great pedagogy? Nine claims from research. National College

for School Leadership Available at

<https://docs.google.com/viewer?url=https://assets.publishing.service.gov.uk/government/uploads/system/uploads Lattachment data/file/329746/what-makes-great-pedagogy-nine-claims-from-research.pdf $>$ [Accessed 27 November 2021]

Peterson, C., 2003. Bringing ADDIE to life: Instructional design at its best. Journal of Educational Multimedia And Hypermedia, 12(3), pp 227-241.

Phillips, W. O., 2008. A study of instructor persona in the online environment (Order No. 3319267). ProQuest Dissertations \& Theses Global. (89210364). Available at <http://ccl.idm.oclc.org/login?url=https://search-proquestcom.ccl.idm.oclc.org/docview/89210364?accountid=10141>[Accessed 27 November 2021]

Powers, K., 2019. Examining current institutional outsourcing practices and the IPEDS human

resources survey component. (NPEC 2019). U.S. Department of Education. Washington, DC: National Postsecondary Education Cooperative. Available at < from http://nces.ed.gov/pubsearch> [Accessed April 11, 2021].

Riter, P., 2017. Five myths about online program management. Educause Review Available at $<$ https://er.educause.edu/articles/2017/3/five-myths-about-online-program-management $>$ [Accessed June 20, 2018]

Russell, A., 2015. Online teaching as a catalyst for re-examining pedagogical assumptions. Journal on Excellence in College Teaching, 26(3), pp 57-91.

Salomon, G., 2003. Distributed cognitions: psychological and educational considerations.

Cambridge: Cambridge University Press.

Schmoyer, A., 2020. Exploring the organizational impact \& planning for the future in OPM Partnerships at a private university. Available at <https://ir.vanderbilt.edu/bitstream/handle/1803/16336/SchmoyerA2020 Andrea\%20Schmoyer.pdf?sequence=1\&i sAllowed $=y>$ [Accessed 27 November 2021]

Springer, S., 2018. One university's experience partnering with an online program management (OPM) provider: A Case Study. Online Journal of Distance Learning Administration. 21(1). Available at $<$ https://www.westga.edu/ distance/ojdla/spring211/springer211.html> [Accessed November 20, 2020].

Strauss, A., and Corbin, J., 1994. Grounded theory methodology: An overview. In N. K. Denzin \& Y. S. Lincoln (Eds.), Handbook of qualitative research (p. 273-285). Los Angeles: Sage Publications, Inc.

Vasser, N., 2010. Instructional design processes and traditional colleges. Online Journal of Distance Learning

Administration, 13(4), pp 61-63.

You, J., 2010. A study of faculty members' perceived utilization of best practices in distance learning course design and delivery and the role of instructional designers (Unpublished doctoral dissertation). University of Toledo, Toledo, $\mathrm{OH}$. Available at < https://eric.ed.gov/?id=ED519784 $>$ [Accessed 27 November 2021] 